Article

\title{
Spatial Correlation between Type of Mountain Area and Land Use Degree in Guizhou Province, China
}

\author{
Yuluan Zhao ${ }^{1,2}$ and Xiubin $\mathrm{Li}^{2, *}$ \\ 1 School of Geographic and Environmental Sciences, Guizhou Normal University, Guiyang 550001, China; \\ zhaoyl.09b@igsnrr.ac.cn \\ 2 Institute of Geographic Sciences and Natural Resources Research, Chinese Academy of Sciences, \\ Beijing 100101, China \\ * Correspondence: lixb@igsnrr.ac.cn; Tel.: +86-10-6488-9297
}

Academic Editors: Fausto Cavallaro and Marc A. Rosen

Received: 17 May 2016; Accepted: 24 August 2016; Published: 29 August 2016

\begin{abstract}
A scientific definition of the type of mountain area and an exploration of the spatial correlation between different types of mountain areas and regional land use at the county level are important for reasonable land resource utilization and regional sustainable development. Here, a geographic information system was used to analyze digital elevation model data and to define the extent of mountainous land and types of mountain areas in Guizhou province. Exploratory spatial data analysis was used to study the spatial coupling relation between the type of mountain area and land use degree in Guizhou province at the county level. The results were as follows: (1) Guizhou province has a high proportion of mountainous land, with a ratio of mountainous land to non-mountainous land of 88:11. The county-level administrative units in Guizhou province were exclusively mountainous, consisting of eight semi mountainous counties, nine quasi mountainous counties, 35 apparently mountainous counties, 13 type I completely mountainous counties, and 23 type II completely mountainous counties; (2) The land use degree at the county level in Guizhou province have remarkable spatial differentiation characteristics. Counties with a high cultivation coefficient are mainly located in the western area along the line between Yinjiang county and Anlong county in west Guizhou province. Counties with a large proportion of construction land or a high integrated index of land use degree are mainly distributed in the economically developed area of central Guizhou province, including parts of the counties (districts/cities) administrated by Guiyang, Zunyi, Liupanshui, Anshun, Duyun, and Kaili; (3) County-level administrative units with relatively flat topography and a low proportion of mountainous land have a large proportion of construction land and a large degree of regional land exploitation. However, the extent of cultivation of county-level administrative units under similar topography differs considerably; (4) The increase in urban land intensity and the decrease in cultivated land intensity are distinctive features of land system change in mountain areas, which is conducive to the sustainable development of mountain.
\end{abstract}

Keywords: type of mountain area; land use intensity; spatial correlation; exploratory spatial data analysis (ESDA); sustainability

\section{Introduction}

Effective exploitation of land resources, the source of resources, and the environmental effects, together with the regional sustainable development of mountain areas (mountainous land) are a research hotspot [1-5]. Human land use activities in mountain areas are likely to cause soil erosion, landslide hazards, and human-wildlife conflict. Farming practices, topography, and slope have significant impacts on soil erosion and sediment delivery in a mountain catchment [6-8]. Mining and construction can also provoke landslides $[9,10]$. Ecological compensation is the key to allocation of land 
resources and sustainable development of mountain areas [11]. We focused on the spatial correlation between different mountain areas and land use. Mountainous land refers to land over a certain altitude, which reflects the natural attributes of a region. In contrast, the term mountain area highlights the global nature and integrity of a region, which is a regional synthesis that includes both natural and humanistic attributes $[12,13]$. When restricted by the topographical relief of mountainous land, the costs of regional land resource utilization and exploitation are very high; roads, communication, water and power supplies, and other infrastructure are lacking; the level of economic development is very low $[14,15]$. Scientific mountain demarcation and mountain area divisions can provide the basis to manage the exploitation of mountain areas and implement appropriate policies.

Methods for the classification of mountainous land and mountain areas have received considerable attention. Currently, remote sensing (RS), geographic information systems (GIS), and digital elevation models (DEM) are used to extract the relief of land surfaces, slope of landforms, and other topographical information [16-19]. A key to calculating the relief of a land surface is to determine the size of a moving window using a two-point change of the mean value [12]. According to the mountainous land classification system of the United Nations Environment Programme (UNEP) [20,21], and given the situation in China [22], a mountainous land classification system for Guizhou province has been determined, and the scope of the spatial distribution as well as the area of mountainous land have been extracted. The types of mountain area at the county level are classified on the basis of extracted mountain information. This classification is beneficial to the establishment and implementation of policies for the development of mountain areas, and is pertinent and effective. This is critical for the development of mountain areas that are restricted by outdated infrastructure, rugged topography, and remote locations [23].

Land provides space for the development of a regional society and economy. The regional land use pattern reflects the developmental stage and level of the regional society and economy [24-26]. Zhuang et al. [27] found that there is a topographic-polar pattern in terms of land use degree from the eastern coastal area to the Qinghai-Tibet Plateau in China, i.e., a decrease in land use degree with increasing altitude, although the relief of the land surface, gradient of landforms, and other topographical factors were not considered in the factor analysis undertaken in their study. However, altitude, relief of the land surface, gradient of landforms, and other topographical factors were considered in the classification of mountainous land and mountain areas. An exploration of the spatial correlation between different types of mountain area and regional land use degree is important for managing the development of mountain areas and optimizing the land resource arrangements in mountain areas. Regional land use degree is characterized by the proportion of construction land, cultivation coefficient, and the integrated index of land use degree. Exploratory spatial data analysis (ESDA) was used to analyze the spatial correlation between the types of mountain area and land use degree [28-31]. This technique visually depicts the spatial distribution pattern of the types of mountain area and land use degree, identifies their spatial aggregation and spatial variation, and reveals the mechanisms of spatial interaction between the two factors.

In this study, we used ESDA to empirically determine the spatial correlation between the different types of mountain area and land use degree in Guizhou province. The objective of this study was to provide a reference for the sustainable development and optimal land resource arrangement of Guizhou province that could be extended to the entire west China region.

\section{Materials and Methods}

\subsection{Study Area}

Guizhou province is located in the eastern Yunnan-Guizhou Plateau, southwest China (Figure 1). The area of the province is $176,167 \mathrm{~km}^{2}$. It is characterized by plateaus, hills, and basins, with $92.5 \%$ of the area being classed as mountains or hills. Carbonate rock is widely distributed in the study area, accounting for $73.8 \%$ of the surface geology. It is therefore a typical karst mountain province. The 
study area has a subtropical humid monsoon climate. The annual average temperature is $24.8^{\circ} \mathrm{C}$, and the annual average rainfall is $1108.2 \mathrm{~mm}$. The vertical climate difference is great and local microclimates are significant. The vegetation is largely subtropical evergreen broad-leaved forest. At the end of 2010, the total population was 34,790,000. The urbanization rate of Guizhou province was $33.8 \%$ and its gross domestic product (GDP) was 4602.16 billion Yuan. The proportion of the three industrial categories was 14:39:47. The GDP per capita was 13,228 Yuan. The disposable income per capita for urban residents was 14,143 Yuan and the net income per capita of farmers was 3472 Yuan. In brief, the province is characterized by typical mountain areas, widely distributed mountainous land, outdated communication networks, water conservancy projects, and low levels of industrialization and urbanization. The level of land resource utilization in this region could be improved. Therefore, Guizhou province is considered an underdeveloped and underexploited region in west China.

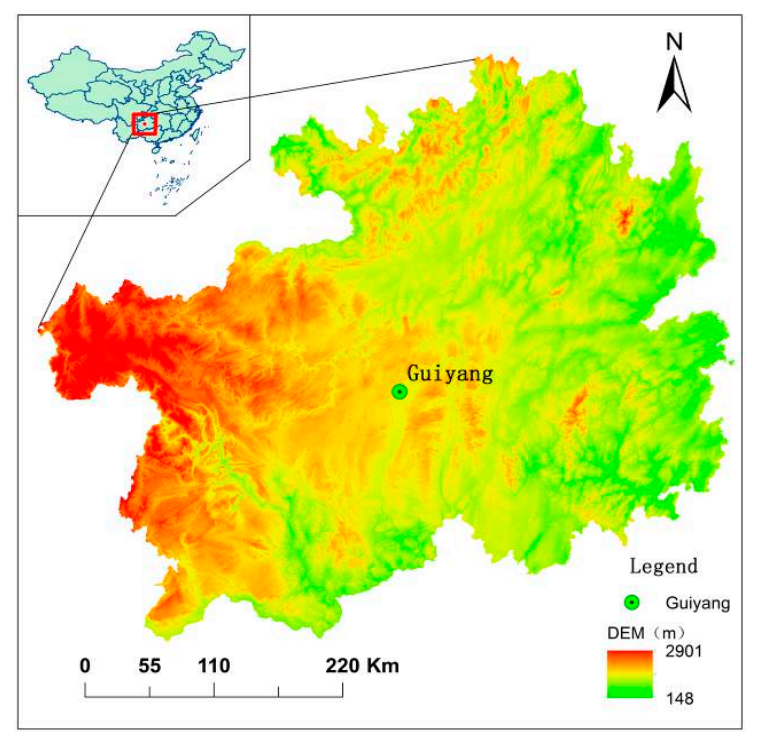

Figure 1. Location of Guizhou Province.

\subsection{Data Sources}

The mountain area was classified using DEM data. The basic grid unit was $30 \mathrm{~m}$, and the format of the data was GRID. Land use information was obtained from the eco-environment change research project in Guizhou province, as deciphered by Thematic Mapper (TM) images in 2010. The basic geographical information of these 88 county-level administrative units was taken from the State Key Laboratory for Mountainous Land Information Systems and Eco-Environment Protection in Guizhou province [13-15]. ArcGIS was used to produce a grid graph of the relief of the land surface and slope, and to extract the area of mountainous land. GeoDa software was used to analyze the spatially coupled features of the type of mountain area and the index of land use degree at the county level.

\subsection{Study Methods}

\subsubsection{Mountain Demarcation and Mountain Area Divisions}

A premise for the classification of a mountain area is required for the effective extraction of regional mountain area. The relief of the land surface and slope are important topographic factors for extracting the scope of a mountain. During calculation of the relief of the land surface, the optimal size of the statistical unit is critical. Based on the mountainous land classification system of UNEP $[20,21]$ and the findings of Chinese scholars [22], and by considering the actual altitude, terrain, slope, relief of the land surface, and other topographic factors, the mountainous land in Guizhou province was classified into hill, low-mountain, low-middle mountain, middle-mountain, or sub-alpine mountain 
(Table 1). The relief of the land surface is the difference between the highest and lowest altitudes in an area. The moving window GIS method was used to calculate the regional relief of the land surface from DEM data. A grid graph was derived from the difference between the maximal and minimal values of the neighboring elevation of every grid in a certain window. The mean grid value of all the relief of land surface values was considered to be the mean relief of the land surface in a region. The possible size of the moving windows used for calculating the mean relief of the land surface was within the range of $3 \times 3$ to $135 \times 135$ pixels. A logarithmic curve was drawn with the window area as the $X$ axis, and the mean relief of the land surface as the $Y$ axis. As the area of the moving window increased, the regional relief of the land surface increased rapidly. When the window area was increased to a certain value, the altitudinal difference increased slowly. The area of the moving window that matched the inflection point was considered to be the optimal statistical unit. The two-point change of mean value method was used to determine the size of the moving window [12].

Table 1. Index used to define the types of mountainous land in Guizhou province.

\begin{tabular}{cccc}
\hline Type of Mountain & Altitude $(\mathbf{m})$ & Relief of the Land Surface $(\mathbf{m})$ & Slope $\left(^{\circ}\right)$ \\
Hill & $<500$ & $\geq 50$ & - \\
Low mountain & $501-1000$ & Relief of the land surface within $6.50 \mathrm{~km}^{2} \geq 200$ & - \\
Low-middle mountain & $1001-1500$ & - & $\geq 5$ \\
Middle mountain & $1501-2500$ & - & $\geq 2$ \\
Sub-alpine mountain & $\geq 2500$ & - & \\
\hline
\end{tabular}

Counties (districts/cities) are important administrative units for social and economic management in China. The classification of mountain areas at the county level will facilitate the relevance and operability of developmental policies in mountainous counties (districts/cities). Based on the mountain information extracted above, the mountain areas were classified according to the proportion of mountainous land area in every county (districts/cities). The 88 counties in Guizhou province were classified according to their proportion of mountainous land in descending order: semi mountainous county, quasi mountainous county, apparently mountainous county, type II completely mountainous county, and type I completely mountainous county (Table 2). There are no lowland or plain counties in Guizhou province.

Table 2. The mountain area classification in Guizhou province.

\begin{tabular}{cc}
\hline Type of Mountain Area & Proportion of Mountain Area \\
\hline Semi mountainous county & $60 \% \leq$ mountain area $<70 \%$ \\
Quasi mountainous county & $70 \% \leq$ mountain area $<80 \%$ \\
Apparently mountainous county & $80 \% \leq$ mountain area $<90 \%$ \\
Type II completely mountainous county & $90 \% \leq$ mountain area $<95 \%$ \\
Type I completely mountainous county & $95 \% \leq$ mountain area $\leq 100 \%$ \\
\hline
\end{tabular}

\subsubsection{Land Use Degree Index}

The index of land use degree in this study includes the proportion of construction land, cultivation coefficient, and integrated index of land use degree. The proportion of construction land is the ratio of construction land to the total land area in a region, which reflects the level of industrialization and urbanization. The cultivation coefficient is the farmland area as a percentage of the total land area in a region, and reflects the extent of the agricultural land resources. The integrated index of land use degree is calculated according to Formula (1) [27]:

$$
L a=\sum_{i=1}^{n} A i \times C i \times 100 \quad L a \in 100,400
$$


Here, $L a$ is the integrated index of land use degree; $A i$ is the hierarchical index of land use degree $i$; and $C i$ is the areal percentage of land use degree $i$.

The hierarchical index of land use degree was determined according to the regional land use intensity (Table 3).

Table 3. Hierarchical value of land use degree.

\begin{tabular}{ccccc}
\hline Type of Land & Uncultivated Land & $\begin{array}{c}\text { Forestland, Grassland, } \\
\text { and Water }\end{array}$ & Agricultural Land & Urban Aggregation Land \\
\hline Grade of land use & $\begin{array}{c}\text { Uncultivated land; } \\
\text { hard-to-use land }\end{array}$ & $\begin{array}{c}\text { Forest land, grass land, } \\
\text { water body }\end{array}$ & $\begin{array}{c}\text { Plowed land, } \\
\text { gardens, artificial } \\
\text { grass land }\end{array}$ & $\begin{array}{c}\text { Urban, residential area, } \\
\text { industrial and mining } \\
\text { land; traffic land }\end{array}$ \\
\hline Index of classification & 1 & 2 & 3 & 4 \\
\hline
\end{tabular}

\subsubsection{Spatial Correlation Analysis}

Spatial correlation analysis refers to the quantitative measurement of the spatial correlation and heterogeneity between geographical phenomena [28]. Spatial correlation analysis includes the establishment of a spatially neighboring matrix and its measurement, and a test of spatial autocorrelation. GeoDa software [29] was used to calculate the spatially neighboring matrix of the 88 counties in Guizhou province. The spatial autocorrelation includes a global and local spatial autocorrelation. The global spatial autocorrelation can describe the total distribution of a certain geographical phenomenon, enabling its spatial aggregation to be determined. The local spatial autocorrelation can depict the location of the spatial distribution of areas with similar aggregation attributes. In this study, the frequently used Global Moran's I and Local Moran's I were used to measure the degree of global and local spatial autocorrelation [30].

The Global Moran's I (I) was calculated as follows:

$$
\begin{gathered}
I=\frac{\sum_{i=1}^{n} \sum_{j \neq 1}^{n} W_{i j}\left(X_{i}-\bar{X}\right)\left(X_{j}-\bar{X}\right)}{S^{2} \sum_{i=1}^{n} \sum_{j \neq 1}^{n} W_{i j}} \\
S^{2}=\frac{1}{n} \sum_{i=1}^{n}\left(X_{i}-\bar{X}\right)^{2} \\
\bar{X}=\frac{1}{n} \sum_{i=1}^{n} X_{i}
\end{gathered}
$$

Here, $X_{i}$ is the observed value of the geographical attribute of study unit $i \bar{X}$ is the mean value of the regional variable; $S^{2}$ is the mean square deviation; and $W_{i j}$ is the matrix of spatial weight $W_{(n \times n)}$, which can be realized by the spatial distance and spatial topology. The normalized $Z_{\text {Score }}$ is frequently used to test the significance level of Moran's I as follows:

$$
Z_{\text {Score }}=\frac{1-E(I)}{\sqrt{\operatorname{Var}(I)}}
$$

Here, $E(I)$ and $\operatorname{Var}(I)$ represent the expected value and square deviation of Moran's I, respectively. When $\left|Z_{\text {Score }}\right|>1.96(\alpha=0.05)$, the $H_{0}$ hypothesis can be rejected (no spatial autocorrelation exists in the attributed value of $n$ pieces of spatial objects), and variables have significant spatial autocorrelation. $I \in[-1,1] . I>0$ indicates a positive global spatial autocorrelation; $I<0$ indicates a negative correlation, and a large absolute value suggests a high degree of correlation. $I=0$ suggests a random distribution and no spatial autocorrelation exists. 
The Local Moran's I $\left(I_{i}\right)$ was calculated as follows:

$$
I_{i}=Z_{i} \sum_{j=1}^{n} W_{i j} Z_{j}(i \neq j)
$$

Here, $Z_{i}$ and $Z_{j}$ represent the normalized observed values of units $i$ and $j$, respectively. $Z_{\text {Score }}$ is used to test the degree of significance of the local spatial autocorrelation. $I_{i}>0$ suggests a positive correlation between the study unit $i$ and the surrounding area, i.e., a high value is surrounded by a high value ( $\mathrm{H}-\mathrm{H}$ type) or a low value is surrounded by a low value (L-L type). $I_{i}<0$ suggests a negative correlation between the regional unit $i$ and the surrounding area, i.e., a low value is surrounded by a high value (L-H type) or a high value is surrounded by a low value (H-L type).

\section{Results}

\subsection{Classification of Mountain Areas}

The moving window area and mean relief of the land surface were used to draw scatter plots, produce logarithmic curves, and conduct theoretical tests (Figure 2). The logarithmic curve was $y=68.563 \operatorname{Ln}(x)+268.07$ and the goodness of fit was $R^{2}=0.9446$. The effect of the fitting was very good. Two reflection points were determined by a first and second value change. The size of the moving window to match the first reflection point was $39 \times 39$ pixels and the area was $1.37 \mathrm{~km}^{2}$. The size of the moving window that matched the second reflection point was $85 \times 85$ pixels and the area was $6.50 \mathrm{~km}^{2}$. Guizhou is situated on the Yun-Gui plateau and has a large topographic relief. The area of the moving window that matched the reflection point determined by the second value change was consistent with the macroscopic topography of Guizhou province. Therefore, $6.50 \mathrm{~km}^{2}$ was considered to be the optimal statistical unit of topographic relief in Guizhou.

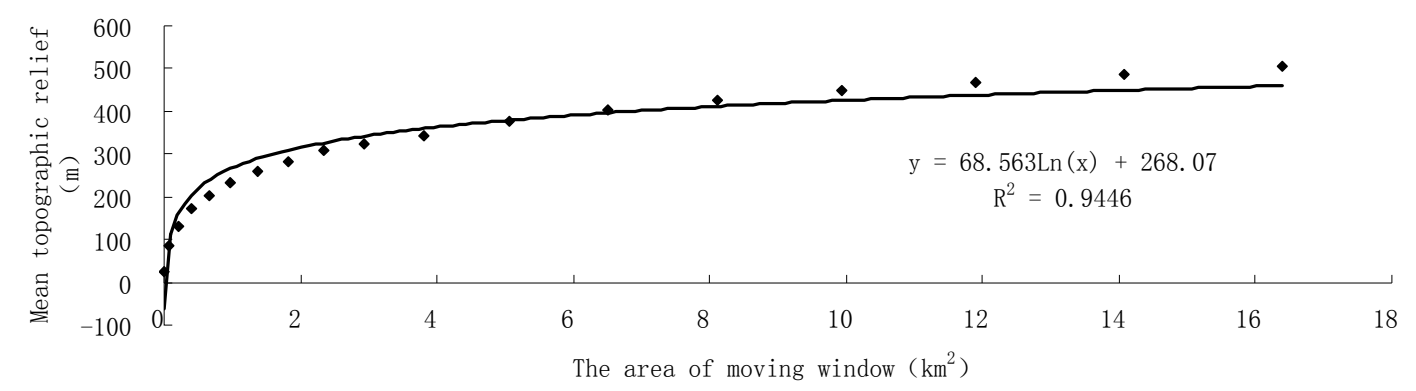

Figure 2. The curve fit between the area of the moving window and mean relief.

Based on the classification standard of mountainous land (Table 1), the area of mountainous land in Guizhou province was $155,191.79 \mathrm{~km}^{2}$, accounting for $88.09 \%$ of the total area. The area of non-mountainous land was $20,978.95 \mathrm{~km}^{2}$, accounting for $11.91 \%$ of the total area. The area of low mountain was $64,923.26 \mathrm{~km}^{2}$, which accounted for $36.85 \%$ of the total area and was the most common mountain class. The area of low-middle mountain was $57,274.64 \mathrm{~km}^{2}$, which accounted for $32.51 \%$ of the total area and was the second most common mountain class. The area of middle mountain was $28,488.04 \mathrm{~km}^{2}$, which accounted for $16.17 \%$ and was the third most common mountain class. The hill and sub-alpine mountain areas were relatively small at 4084.61 and $421.25 \mathrm{~km}^{2}$, accounting for $2.32 \%$ and $0.24 \%$, respectively. The mountainous land in Guizhou province was characterized by a large scope, wide extent, and clear spatial differences (Figure 3). The sub-alpine mountain and middle mountain classes were mainly distributed in Bijie city and Liupanshui city in the west of Guizhou province, with only a few areas distributed in the Wuyi, Leigong, and Dalou mountain ranges. Low-middle mountains were mainly distributed in central Guizhou province. Low mountain was mainly distributed along the northward, eastward, and southward transition belts in the central 
Guizhou Plateau. Hills were mainly distributed in Guizhou Plateau and the transitional belt in West Hunan. Non-mountainous land was mainly distributed in central Guizhou province and the valley area in East Guizhou province.

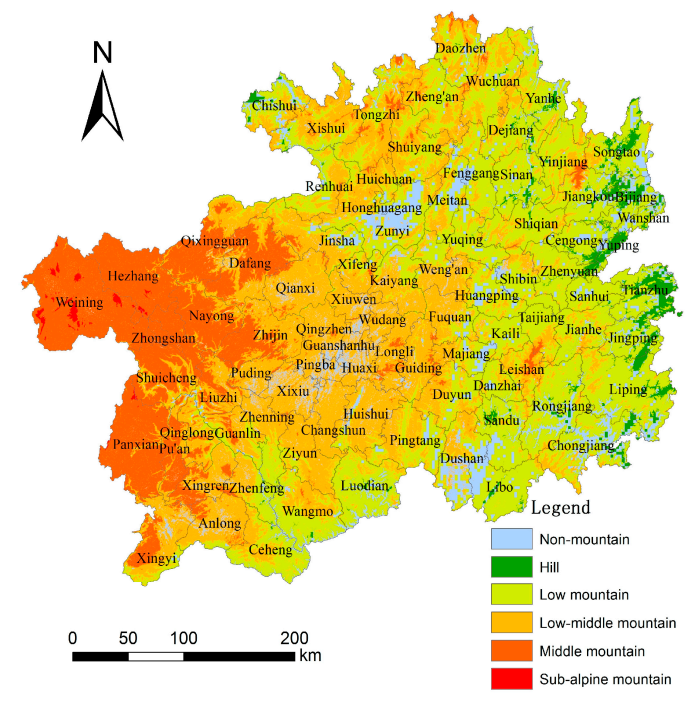

Figure 3. Distribution of mountainous land in Guizhou province.

According to the classification standard in Table 2, the 88 county-level administrative units in Guizhou province were classed as mountainous (Table 4), including semi mountainous, quasi mountainous, apparently mountainous, type II completely mountainous, and type I completely mountainous counties. There were no hill and plain counties in the province. Specifically, there were eight semi mountainous counties, which were mainly distributed in the flat area of central Guizhou province; there were nine quasi mountainous counties, which were mainly distributed in central Guizhou province, the Chishui Valley, and east Guizhou Valley; there were 13 type I completely mountainous counties, which were mainly distributed in the Wumeng, Daloushan, Wuyi, and Miaoling mountain areas; there were 23 type II completely mountainous counties, which were mainly distributed in the areas surrounding the type I completely mountainous counties; and there were 35 apparently mountainous counties, which were mainly distributed in the middle-east and south of Guizhou province (Figure 4).

Table 4. Summary of mountainous counties in Guizhou Province.

\begin{tabular}{|c|c|}
\hline Type of Mountain Area & Name of County (Region, City, Special Zone) \\
\hline Semi mountainous county & Nanming, Xixiu, Huaxi, Pingba, Honghuagang, Guanshanhu, Dushan, Baiyun \\
\hline Quasi mountainous county & Libo, Chishui, Qingzhen, Majiang, Meitan, Yuping, Chongjiang, Bijiang, Zunyi \\
\hline Apparently mountainous county & $\begin{array}{l}\text { Si'nan, Pingtang, Xingyi, Xifeng, Xingren, Guiding, Yuqing, Liping, Tianzhu, } \\
\text { Fenggang, Yanhe, Luodian, Longli, Jiangkou, Kaiyang, Anlong, Zhenfeng, } \\
\text { Fuquan, Shibin, Jingping, Jinsha, Weng'an, Songtao, Cengong, Puding, Sandu, } \\
\text { Huishui, Changshun, Qianxi, Rongiang, Wanshan, Yunyan, Huangping, } \\
\text { Xiuwen, Wudang }\end{array}$ \\
\hline Type II completely mountainous county & $\begin{array}{l}\text { Zhenyuan, Pu'an, Wuchuan, Ziyun, Qinglong, Dafang, Jianhe, Tongzi, Zhijin, } \\
\text { Dejiang, Kaili, Renhuai, Danzhai, Huichuan, Duyun, Guanling, Ceheng, Xishui, } \\
\text { Daozhen, Sanhui, Zhenning, Wangmo, Liuzhi }\end{array}$ \\
\hline Type I completely mountainous county & $\begin{array}{l}\text { Taijiang, Hezhang, Leishan, Weining, Panxian, Shuicheng, Zhongshan, Nayong, } \\
\text { Yinjiang, Shiqian, Zheng'an, Shuiyang, Qixingguan }\end{array}$ \\
\hline
\end{tabular}




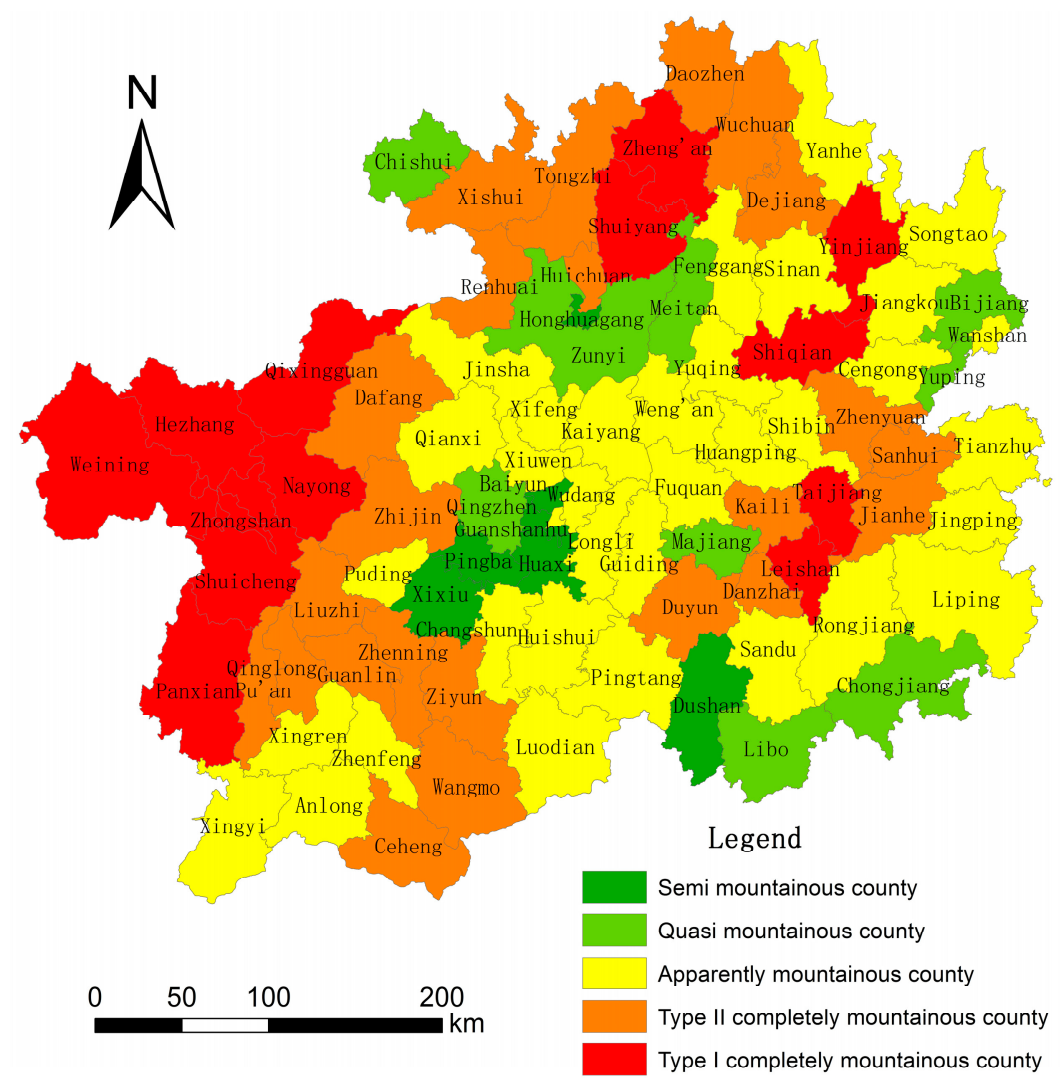

Figure 4. Distribution of mountainous counties in Guizhou Province.

\subsection{Index of Land Use Degree}

The integrated index of land use degree, proportion of construction land, and cultivation coefficient were all used to measure the land use degree in Guizhou province at the county level. The natural breakpoint method was used to produce a map of the distribution of land use degree in Guizhou province (Figure 5). Figure 5a shows that the county-level administrative units with a high proportion of construction land in Guizhou province were distributed mainly in the relatively developed region of the central Guizhou economic area. The ten administrative units with the largest proportion of construction land were Nanming, Yunyan, Guanshanhu, Baiyun, Honghuagang, Zhongshan, Huaxi, Huichuan, Xixiu, and Pingba. The proportion of construction land in the Nanming district of Guiyang was $50.82 \%$. Figure $5 \mathrm{~b}$ shows that the county-level administrative units with a high cultivation coefficient in Guizhou province were mainly distributed in the western area along the line connecting Yinjiang county and Anlong county, including counties with a high proportion of mountain area. This region has a relatively high altitude and a vulnerable eco-environment. The ten county-level administrative units with the largest cultivation coefficients were Qianxi, Pingba, Puding, Xixiu, Weining, Renhuai, Zhenfeng, Qingzhen, Xiuwen, and Zunyi county. The cultivation coefficient of Qianxi county was $52.22 \%$. Figure $5 \mathrm{c}$ shows that the county-level administrative units with a high index of integrated land use degree in Guizhou province were mainly distributed in the central Guizhou economic area. The ten county-level administrative units with the highest index of integrated land use degree were Nanming, Guanshanhu, Yunyan, Baiyun, Honghuagang, Qianxi, Pingba, Zhongshan, Xixiu, and Puding. 


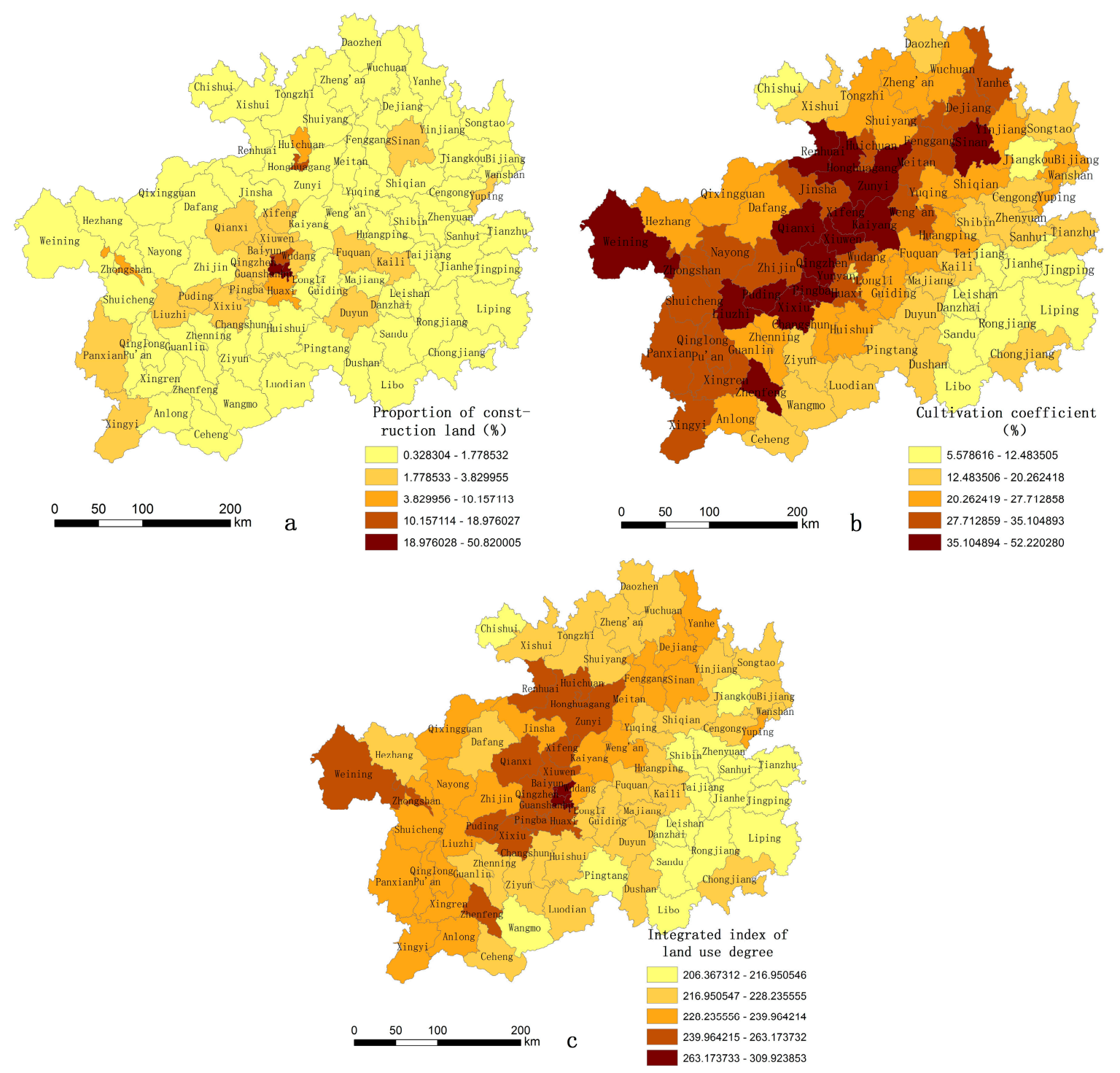

Figure 5. Distribution of land use degree in Guizhou province. (a) Proportion of construction land; (b) Cultivation coefficient; (c) Integrated index of land use degree.

\subsection{Spatial Correlation between Types of Mountain Area and Land Use Degree}

\subsubsection{Global Spatial Autocorrelation Analysis}

To analyze the spatial distribution between types of mountain area and land use degree in Guizhou province at the county level, the Global Moran's I index values of the proportion of mountainous land area, proportion of construction land, cultivation coefficient, and integrated index of land use degree of 88 county-level administrative units were calculated as $0.4880,0.6140,0.5908$, and 0.7210 , respectively (Table 5). The results suggested that the four variables mentioned above have a marked autocorrelation and clear aggregation characteristics, i.e., both high and low values for counties/districts that neighbor each other. Both satisfied the significance test at $\alpha=0.05$. The Global Moran's I index of the proportion of mountainous land area was low, suggesting a low degree of spatial aggregation and a relative evenness of mountainous land in Guizhou province. It also suggests that the degree of spatial aggregation of the natural elements of the mountainous land area in Guizhou province was lower than for the humanistic elements. 
Table 5. Global spatial autocorrelation analysis results.

\begin{tabular}{ccccc}
\hline Type of Index & $\begin{array}{c}\text { Proportion of } \\
\text { Mountainous } \\
\text { Land Area }\end{array}$ & $\begin{array}{c}\text { Proportion of } \\
\text { Construction Land }\end{array}$ & $\begin{array}{c}\text { Cultivation } \\
\text { Coefficient }\end{array}$ & $\begin{array}{c}\text { Index of } \\
\text { Integrated Land } \\
\text { Use Degree }\end{array}$ \\
\hline$I$ & 0.4880 & 0.6140 & 0.5908 & 0.7210 \\
$E(I)$ & -0.0115 & -0.0115 & -0.0115 & -0.0115 \\
$Z_{\text {Score }}$ & 7.1971 & 10.5668 & 8.8176 & 11.7922 \\
Threshold value $(\alpha=0.05)$ & 1.96 & 1.96 & 1.96 & 1.96 \\
\hline
\end{tabular}

The Global Moran's I index of land use degree was highest for the integrated index of land use degree, followed by the proportion of construction land and cultivation coefficient. This suggests that the cultivation coefficient has a relatively even spatial distribution and low degree of spatial aggregation. In contrast, the degree of autocorrelation of the proportion of construction land and the integrated index of land use degree were high, suggesting a remarkable spatial aggregation.

\subsubsection{Local Spatial Autocorrelation Analysis}

The Local Moran's I index was used to analyze the local spatial aggregation characteristics of the types of mountain area and index of land use degree in Guizhou province at the county level (Table 6). In terms of the proportion of mountainous land area in each county, the Local Moran's I index value ranged from -0.6542 to 4.2146 . The magnitude of the range was 4.8688 and the mean value was 0.4825 . The mean values of the Local Moran's I for the proportion of construction land, cultivation coefficient, and integrated index of land use degree were $0.6071,0.5841$, and 0.7128 , respectively. All three values were higher than the mean value of the Local Moran's I of the mountainous land area, suggesting a high degree of spatial aggregation of the land use degree in Guizhou province at the county level. The county-level administrative unit with the highest Local Moran's I value for the proportion of construction land was Nanming district, Guiyang city, with a local Moran's I of 17.0227. Longli county in Qian'nan state had the lowest Local Moran's I of -0.6672 . The magnitude of the range between Nanming district and Longli county was 17.6899. The county-level administrative unit with the highest local Moran's I value for the cultivation coefficient was Puding county, Anshun city, with a value of 2.5650. Chishui city had the lowest Local Moran's I value of -0.8764 . The range between Puding county Chishui city was the lowest, with a value of 3.4414 .

Table 6. Local spatial autocorrelation analysis results.

\begin{tabular}{ccccc}
\hline Type of Index & Minimal Value & Maximal Value & Mean Value & Range \\
\hline Proportion of mountainous land area & -0.6542 & 4.2146 & 0.4825 & 4.8688 \\
Proportion of construction land & -0.6672 & 17.0227 & 0.6071 & 17.6899 \\
Cultivation coefficient & -0.8764 & 2.5650 & 0.5841 & 3.4414 \\
Integrated index of land use degree & -0.9534 & 10.5507 & 0.7128 & 11.5041 \\
\hline
\end{tabular}

To visually determine the types and characteristics of the spatial distribution of the proportion of mountainous land area and the index of land use degree in Guizhou province at the county level, GeoDa software was used to produce the Local Indicator of Spatial Association (LISA) aggregation graph of the proportion of mountainous land and index of land use degree (Figure 6).

(1) Local spatial autocorrelation analysis of the index of the proportion of mountainous land

Twenty-two county-level administrative units were locally positively correlated in terms of the index of the proportion of mountainous land area (Figure 6a), with $11 \mathrm{H}-\mathrm{H}$ types and $11 \mathrm{~L}-\mathrm{L}$ types. The H-H type counties (districts/cities) were mainly located in: (1) the Wumeng mountain area in the west of Guizhou province; (2) the Dalou, Wuling, and Miaoling mountain areas in the north of 
Guizhou province, including the Weining, Hezhang, and Nayong counties of Bijie city, Zhongshan district, and the Shuicheng and Pan counties of Liupanshui city; (3) Pu'an county in the southwest of Guizhou province; and (4) Zheng'an and Tongzi counties of Zunyi city, Yanhe county of Tongren city, and Nantaijiang county in the southeast of Guizhou province. The counties mentioned above, and their surrounding counties, had a high proportion of mountainous land area and aggregating characteristics were identified. The L-L type counties were mainly located in the economically developed area of central Guizhou province, including the Yunyan, Nanming, Guanshanhu, Baiyun, Huaxi, and Wudang districts, Xiuwen county, and Qingzhen city of Guiyang city, Pingba county of Anshun city, and Sandu and Libo counties of Qiannan state. The H-L type counties (regions/cities) were located in Xifeng county and Huichuan district.
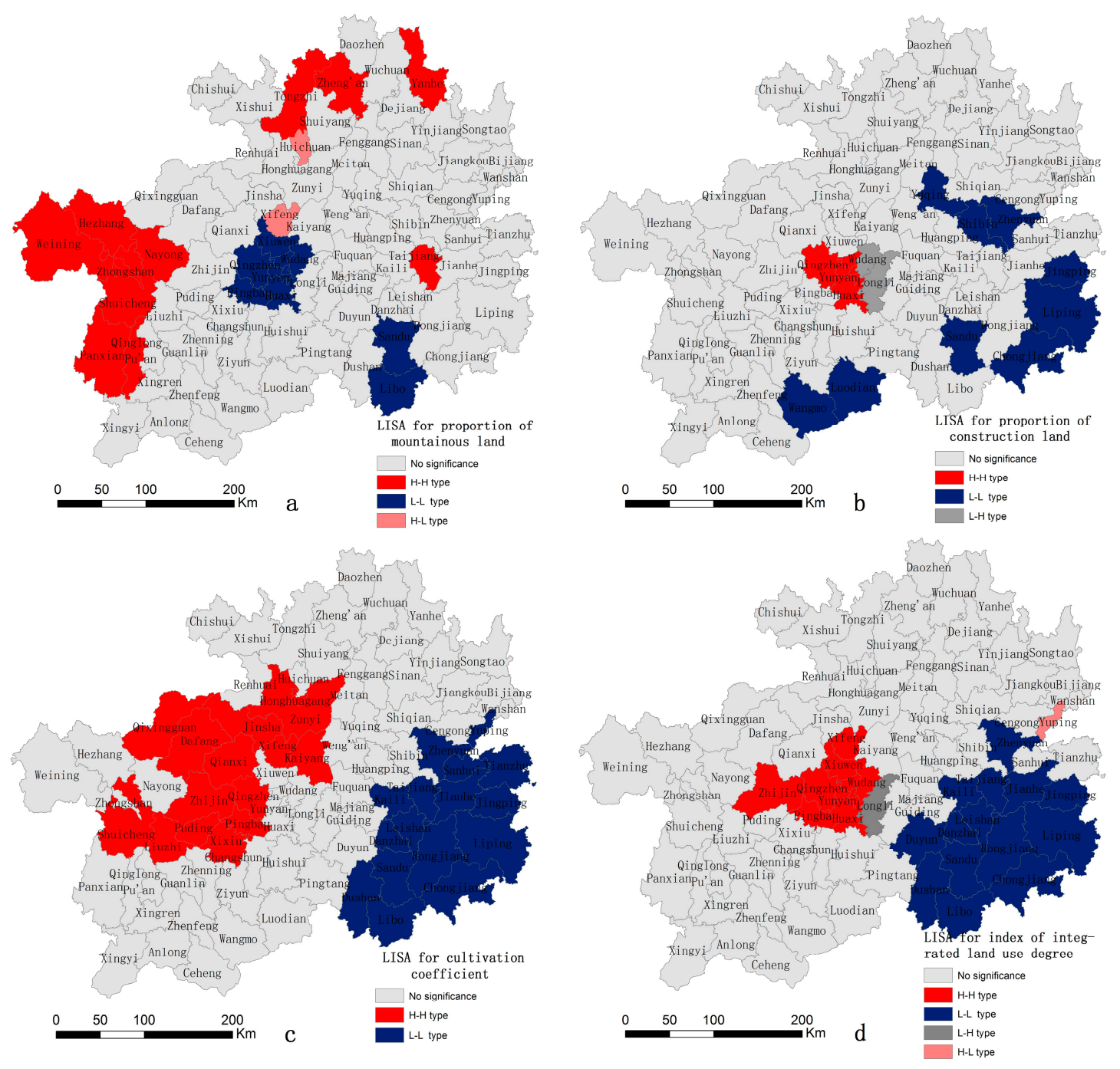

Figure 6. Local Indicator of Spatial Association (LISA) aggregation maps for the proportion of mountainous land and index of land use degree in every county of Guizhou province. (a) LISA for proportion of mountains land; (b) LISA for proportion of construction land; (c) LISA for cultivation coefficient; (d) LISA for index of integrated land use degree.

(2) Local spatial autocorrelation analysis of the index of land use degree

Fifteen county-level administrative units were locally positively correlated in terms of the proportion of construction land (Figure 6b), with $6 \mathrm{H}-\mathrm{H}$ types and $9 \mathrm{~L}-\mathrm{L}$ types. The $\mathrm{H}-\mathrm{H}$ type counties (districts/cities) were mainly located in the economically developed area of central Guizhou province, 
including the economically advanced city of Guiyang and its Yunyan, Nanming, Guanshanhu, Baiyun, and Huaxi districts, as well as Qingzhen city. The L-L type counties (districts/cities) were mainly located in the region administrated by the minority, including Qiandongnan State, Qian'nan State, Shibin, Zhenyuan, Jingping, Liping, and Congjian counties of Qiandongnan State, Sandu, Luodian, and Wangmo counties of Qian'nan State, and Yuqing county of Zunyi city. The L-H type counties (districts/cities) were mainly located in Wudang district and Longli county.

Thirty-one counties (districts/cities) were locally positively correlated in terms of the index of cultivation coefficient (Figure 6c), with $15 \mathrm{H}-\mathrm{H}$ types and $16 \mathrm{~L}-\mathrm{L}$ types. The H-H type counties (districts/cities) were mainly located in densely populated counties (districts/cities) in West Guizhou province, including Qixingguan district, Dafang, Jinsha, Qianxi, and Zhijing counties of Bijie city, Qingzhen city, Xifeng, and Kaiyang counties of Guiyang city, Xixiu district, Puding and Pingba counties of Anshun city, Liuzhi district and Shuicheng county of Liupanshui city, and Huagang district and Zunyi county of Zunyi city. The L-L type counties (districts/cities) were mainly located in sparsely populated regions in southeast Guizhou province, including Kaili city, Zhenyuan, Sanhui, Tianzhu, Taijiang, Leishan, Jianhe, Jingping, Chongjiang, and Rongjiangg counties in Qiandongnan State, Danzai, Sandu, Dushan, and Libo counties in Qiannan State, and Yuping county in Tongren city.

Twenty-five counties (districts/cities) were locally positively correlated in terms of the index of integrated land use degree (Figure 6d), with $11 \mathrm{H}-\mathrm{H}$ and $14 \mathrm{~L}-\mathrm{L}$ types. The H-H type counties (districts/cities) were located in the economically developed area of central Guizhou province, including the economically advanced city of Guiyang and the surrounding districts/counties, including Yunyan, Nanming, Guanshanhu, Baiyun, and Huaxi districts, Qingzhen city, Xiuwen county, Wudang district, Xifeng county, Zhijin county of Bijie city, and Pingba county of Anshun city. The L-L type counties (districts/cities) were mainly distributed in southeast Guizhou province, including Kaili city, Zhenyuan, Taijiang, Leishan, Jianhe, Jingping, Liping, Chongjiang and Rongjiangg counties of Qiandongnan State, Duyun city, and Sandu, Dushan, and Libo counties of Qiannan State. Two counties (districts/cities) were locally negatively correlated in terms of the index of integrated land use degree. The L-H type counties (districts/cities) were located in Longli county of Qiannan State. The only H-L type county was Yuping county of Tongren city.

\subsubsection{Spatial Coupling Analysis between the Type of Mountain Area and Regional Land Use}

To analyze the spatial coupling correlation between the type of mountain area and regional land use in Guizhou province at the county level, the type of local spatial autocorrelation was analyzed statistically in terms of the index of mountain area and index of regional land use degree in Guizhou province at the county level (Table 7). There were six counties (districts/cities) whose spatial distribution of the proportion of construction land was the $\mathrm{H}-\mathrm{H}$ type, and their indices of mountainous land area were the L-L type. This shows that counties (districts/cities) with little mountainous land and a relatively even topography had a large proportion of construction land and a high degree of regional development. There were ten counties (districts/cities) whose spatial distribution of the integrated index of land use degree was the H-H type. In particular, there were nine counties (districts/cities) whose spatial distribution of the proportional index of mountainous land area was the $\mathrm{H}-\mathrm{H}$ type. This also indicates a low proportion of mountainous land and high degree of regional land use degree. There were four counties (districts/cities) whose spatial distribution of the proportional index of mountainous land area was the L-L type. In particular, there were two counties (districts/cities) whose cultivation coefficient was the $\mathrm{H}-\mathrm{H}$ type, and proportional index of mountainous land area was the L-L type. This suggests that the cultivation degree differed considerably under similar topographic conditions. This difference was probably related to their urban population density (districts/cities). The high cultivation coefficient in some counties with a high proportion of mountainous land would probably lead to adverse environmental effects during regional sustainable development. 
Table 7. The local spatial autocorrelation between mountainous land area and the index of land use degree.

\begin{tabular}{cccccccccc}
\hline \multirow{2}{*}{$\begin{array}{c}\text { Spatial Distribution of } \\
\text { Mountainous Land }\end{array}$} & \multicolumn{6}{c}{ Spatial Distribution of the Index of Land Use Degree } \\
\cline { 2 - 9 } & $\begin{array}{c}\text { Proportion of } \\
\text { Construction Land }\end{array}$ & $\begin{array}{c}\text { Cultivation } \\
\text { Coefficient }\end{array}$ & $\begin{array}{c}\text { Index of Integrated Land } \\
\text { Use Degree }\end{array}$ \\
\cline { 2 - 9 } & H-H & L-L & L-H & H-H & L-L & H-H & L-L & L-H & H-L \\
\hline H-H & 0 & 0 & 0 & 1 & 1 & 0 & 1 & 0 & 0 \\
L-L & 6 & 1 & 1 & 2 & 2 & 9 & 2 & 0 & 0 \\
H-L & 0 & 0 & 0 & 1 & 0 & 1 & 0 & 0 & 0 \\
Proportion of construction land & 6 & 1 & 1 & - & - & - & - & - & - \\
Cultivation coefficient & - & - & - & 4 & 3 & - & - & - & - \\
Integrated index of land use degree & - & - & - & - & - & 10 & 3 & 0 & 0 \\
\hline
\end{tabular}

H-H: high value surrounded by a high value; L-L: low value surrounded by a low value; L-H: low value surrounded by a high value; H-L: high value surrounded by a low value.

\section{Discussion and Conclusions}

In this study, GIS technology was used to treat the DEM data and to extract the area and spatial scope of every kind of mountain area in Guizhou province. The type of mountain area of 88 counties (districts/cities) in Guizhou province was classified. The ESDA method was used to study the spatial coupling correlation between the type of mountain area and land use degree in Guizhou Province at the county level. The following conclusions can be made.

(1) Guizhou province has a high proportion of mountain area. The ratio of mountain area to non-mountain area is $88: 11$. The administrative units in Guizhou province at the county level are exclusively mountainous counties. In terms of our classification system, there were eight semi mountainous counties, nine quasi mountainous counties, 35 apparently mountainous counties, 13 type I completely mountainous counties, and 23 type II completely mountainous counties.

(2) The land use degree at the county level in Guizhou province was characterized by a remarkable spatial differentiation. The county-level administrative units with high cultivation coefficients were mainly distributed in West Guizhou province along the line connecting Yinjiang and Anlong counties. The county-level administrative units with a large proportion of construction land and a high integrated index of land use degree were mainly located in the economically developed area of central Guizhou province, including parts of the counties administrated by Guiyang, Zunyi, Liupanshui, Anshun, Duyun, and Kaili.

(3) The land use degree among the different types of mountain areas differed considerably. In terms of land use structure, the proportion of mountainous land was very low, while the proportion of construction land was high in county-level administrative units with a relatively flat topography. The degree of regional land exploitation was very high, but under similar topographical conditions, the extent of cultivation in county-level administrative units differed considerably.

(4) Urbanization is an important pathway for economic development and ecological protection in mountain areas [32,33]. The increase of urban land intensity and the decrease of cultivated land intensity are two distinctive features of land system change in mountain areas. Semi mountainous areas that have a small proportion of mountain land are the key regions for the development of urbanization and industrialization in Guizhou province. Because central Guizhou province is the core region for economic development in the region, the pace of urbanization and industrialization should be accelerated in the future, and an intensified land resource utilization level should be encouraged. The carrying capacity of the regional population, and the development of secondary (manufacturing) and tertiary (services) stage industries will be enhanced. Meanwhile, to reduce population density and the cultivation coefficient in mountainous counties, and to protect the regional eco-environment and promote harmonious and sustainable development of mountainous counties in Guizhou province, the agricultural population in surrounding mountainous counties should be accommodated through 
rural-urban migration. This study provides a typical empirical case study of sustainable mountain area development.

Acknowledgments: This work was supported by the national key basic research and development program (2015CB452706), National Natural Science Foundation of China (41361021), and the Science and Technology Foundation of Guizhou (Q J LKS [2013] 17).

Author Contributions: Yuluan Zhao and Xiubin Li developed the original idea for the study. Yuluan Zhao was responsible for data collecting, data analysis, and writing of the manuscript. Xiubin Li reviewed the manuscript.

Conflicts of Interest: The authors declare no conflict of interest.

\section{References}

1. Mihai, N.; Mihai-Gabriel, B.; Andrei, A.; Rusu, E. Digital soil mapping in a mountainous area with mixed land use (Humor catchment-Eastern Carpathians, Romania) using soil-landscape systems, fuzzy logic and environmental covariates. Environ. Eng. Manag. J. 2016, 15, 1-19.

2. Ying, Z.; Li, X.; Wei, S. Determinants of cropland abandonment at the parcel, household and village levels in mountain areas of China: A multi-level analysis. Land Use Policy 2014, 41, 186-192.

3. Hua, X.; Yan, J.; Li, H.; He, W.; Li, X. Wildlife damage and cultivated land abandonment: Findings from the mountainous areas of Chongqing, China. Crop Prot. 2016, 84, 141-149. [CrossRef]

4. Huang, M.; Qi, S.; Shang, G. Karst landslides hazard during 1940-2002 in the mountainous region of Guizhou Province, Southwest China. Nat. Hazards 2011, 60, 781-784. [CrossRef]

5. Sayadi, S.; González-Roa, M.C.; Calatrava-Requena, J. Public preferences for landscape features: The case of agricultural landscape in mountainous Mediterranean areas. Land Use Policy 2009, 26, 334-344. [CrossRef]

6. Alatorre, L.C.; Beguería, S.; Lanarenault, N.; Navas, A.; García-Ruiz, J.M. Soil erosion and sediment delivery in a mountain catchment under scenarios of land use change using a spatially distributed numerical model. Hydrol. Earth Syst. Sci. 2012, 16, 1321-1334. [CrossRef]

7. Sun, W.; Shao, Q.; Liu, J.; Zhai, J. Assessing the effects of land use and topography on soil erosion on the Loess Plateau in China. Catena 2014, 121, 151-163. [CrossRef]

8. Huang, W.; Ho, H.C.; Peng, Y.; Li, L. Qualitative risk assessment of soil erosion for karst landforms in Chahe town, southwest China: A hazard index approach. Catena 2016, 144, 184-193. [CrossRef]

9. Ma, D.; Miao, X.; Bai, H.; Huang, J.; Pu, H.; Wu, Y.; Zhang, G.; Li, J. Effect of mining on shear sidewall groundwater inrush hazard caused by seepage instability of the penetrated karst collapse pillar. Nat. Hazards 2016, 82, 73-93. [CrossRef]

10. Lateltin, O.; Haemmig, C.; Raetzo, H.; Bonnard, C. Landslide risk management in Switzerland. Landslides 2005, 2, 313-320. [CrossRef]

11. Zhou, C.; Svensson, B.M.; Yan, J.; Chen, X.; Li, K. Ecological compensation: A key to sustainable development in the Guizhou Province Karst Region, Southwest China. Open J. For. 2015, 4, 212-222. [CrossRef]

12. Fan, J.; Zhang, Z.; Li, L. Mountain demarcation and mountainous area divisions of Sichuan province. Geogr. Res. 2015, 34, 65-73. (In Chinese)

13. Wang, M.; Zhu, G. Mountains in China; Sichuan Science and Technology Press: Chengdu, China, 1988. (In Chinese)

14. Jiang, X.; Zeng, H. Quantifying mountain regions of China: A case study in Sichuan. J. Mt. Sci. 2009, 27, 24-32. (In Chinese)

15. Zhong, X. Mountain Introduction and Mountain Research of China; Sichuan Science and Technology Press: Chengdu, China, 2000. (In Chinese)

16. Wood, J. The Geomorphological Characterization of Digital Elevation Models; University of Lancaster: Lancaster, UK, 1996.

17. Karátson, D.; Telbisz, T.; Singer, B.S. Late-stage volcano geomorphic evolution of the Pleistocene San Francisco Mountain, Arizona (USA), based on high-resolution DEM analysis and ${ }^{40} \mathrm{Ar} /{ }^{39} \mathrm{Ar}$ chronology. Bull. Volcanol. 2010, 72, 833-846. [CrossRef]

18. Gu, L.; Wang, C.; Li, P.; Wang, J.; Wang, Z. Research on mountain top extraction accuracy based on DEM. Geomat. Inf. Sci. Wuhan Univ. 2016, 41, 131-135. (In Chinese) 
19. Cheng, W.; Wang, N.; Zhao, M.; Zhao, S. Relative tectonics and debris flow hazards in the Beijing mountain area from DEM-derived geomorphic indices and drainage analysis. Geomorphology 2016, 257, $134-142$. [CrossRef]

20. Hassan, R.; Scholes, R.; Ash, N. Ecosystems and Human Well-Being: Current State and Trends: Findings of the Condition and Trends Working Group; Island Press: Washington, DC, USA, 2005.

21. Schuler, M.; Stucki, E.; Roque, O.; Perlik, M. Mountain Areas in Europe: Analysis of Mountain Areas in EU Member States, Acceding and Other European Countries; European Commission: Brussels, Belgium, 2004.

22. Zhong, X.; Liu, S. Research on the mountain classification in China. Mt. Res. 2014, 32, 129-140. (In Chinese)

23. Lu, D.; Liu, W. Analysis of geo-factors behind regional development and regional policy in China. Sci. Geogr. Sin. 2000, 20, 487-493. (In Chinese)

24. Long, H.; Li, X. Analysis on regional land use transition: A case study in transect of Yangtze River. J. Nat. Resour. 2002, 17, 144-149. (In Chinese)

25. Mather, A.S. The forest transition. Area 1992, 24, 367-379.

26. Li, X.; Zhao, Y. Forest transition, agricultural land marginalization and ecological restoration. China Popul. Resour. Environ. 2011, 21, 91-95. (In Chinese)

27. Zhuang, D.; Liu, J. Study on the model of regional differentiation of land use degree in China. J. Nat. Resour. 1997, 12, 105-111. (In Chinese)

28. Xie, H.; Kung, C.; Zhao, Y. Spatial disparities of regional forest land change based on ESDA and GIS at the county level in Beijing-Tianjin-Hebei area. Front. Earth Sci. 2012, 6, 445-452. [CrossRef]

29. Anselin, L.; Syabri, I.; Kho, Y. GeoDa: An introduction to spatial data analysis. Geogr. Anal. 2010, 38, 5-22. [CrossRef]

30. Wang, Z.; Wu, J. Computational Geography; Science Press: Beijing, China, 2011. (In Chinese)

31. Cressie, N.; Kang, E.L. Hot enough for you? A spatial exploratory and inferential analysis of North American climate-change projections. Math. Geosci. 2016, 48, 107-121. [CrossRef]

32. Karen, C.S.; Anette, R.; Christopher, G.B.; Michail, F.; Dagmar, H.; Tobias, L.; Peter, M.; Darla, K.M.; Branislav, O.; David, S. Urban land teleconnections and sustainability. Proc. Natl. Acad. Sci. USA 2012, 109, 7687-7692.

33. Liu, J.; Hull, V.; Batistella, M.; DeFries, R.; Dietz, T.; Fu, F.; Hertel, T.W.; Izaurralde, R.C.; Lambin, E.F.; Li, S.; et al. Framing sustainability in a telecoupled world. Ecol. Soc. 2013, 18, 26. [CrossRef]

(C) 2016 by the authors; licensee MDPI, Basel, Switzerland. This article is an open access article distributed under the terms and conditions of the Creative Commons Attribution (CC-BY) license (http://creativecommons.org/licenses/by/4.0/). 